\title{
Prediction of hemodynamic fluctuations after induction of general anesthesia using propofol in non-cardiac surgery: a retrospective cohort study
}

\author{
Sho Kawasaki ${ }^{1,2}$, Chikako Kiyohara $^{2^{*}}$ (D), Shoji Tokunaga ${ }^{3}$ and Sumio Hoka ${ }^{1}$
}

\begin{abstract}
Background: Although propofol is a common anesthetic agent for the induction of general anesthesia, hemodynamic fluctuations are occasionally prominent during induction/intubation. The aims of this study were to determine the influential factors on enhanced hemodynamic fluctuation and to establish a prediction formula to quickly determine the dose of propofol to protect against hemodynamic fluctuations.

Methods: This retrospective cohort study patients $(n=2097)$ were 18 years or older. They underwent general anesthesia induction using propofol and orotracheal intubation for non-cardiac surgery at Kyushu University Hospital during April 2015 to March 2016. Preoperative patient clinical information was collected from anesthesia preoperative evaluation records. Intraoperative data were obtained from computerized anesthesia records. If patients' post-induction mean arterial blood pressure (MAP) decreased or increased 30\% or more from their pre-induction MAP, they were determined to have enhanced hemodynamic fluctuations. Unconditional logistic regression was used to assess the adjusted odds ratios (ORs) and 95\% confidence intervals (Cls). Structural equation modeling (SEM) was conducted to simultaneously examine the direct and indirect effect (path coefficient $=r$ ) of potential variables.
\end{abstract}

Results: In the SEM analysis, age was significantly associated with enhanced hemodynamic fluctuations (adjusted odds ratio $=1.008,95 \% \mathrm{Cl}=1.001-1.015, P=0.03)$. Age (path coefficient $(r)=-0.0113,95 \% \mathrm{Cl}=-0.0126-0.010, P<0.001$ ), American Society of Anesthesiologists physical status (ASA-PS) $(r=-0.0788,95 \% \mathrm{Cl}=-0.1431-0.0145, P=0.02)$, $\operatorname{sex}(r=0.057,95 \% \mathrm{Cl}=0.0149-0.9906, P=0.01)$, and fentanyl dose $(r=0.1087,95 \% \mathrm{Cl}=0.0707-0.1467, P<0.001)$ influenced the dose of propofol in induction. The prediction formula of "Propofol dose $(\mathrm{mg})=[2.374-0.0113 \times$ age (year) -0.0788 (if ASA-PS 3 or 4) +0.057 (if female) $+0.1087 \times$ fentanyl dose $(\mu \mathrm{g} / \mathrm{kg})] \times$ body weight $(\mathrm{kg})^{\prime \prime}$ was derived.

Conclusions: Age was associated with hemodynamic fluctuations in induction. Although the prediction formula is considered to be acceptable, future studies validating whether it can decrease patients' risk of enhanced hemodynamic fluctuations in clinical situations are necessary.

Keywords: Propofol, Anesthesia induction, Hemodynamics, Prediction formula

\footnotetext{
* Correspondence: chikako@phealth.med.kyushu-u.ac.jp

${ }^{2}$ Department of Preventive Medicine, Graduate School of Medical Sciences,

Kyushu University, Maidashi 3-1-1, Higashi-ku, Fukuoka, Fukuoka, Japan

Full list of author information is available at the end of the article
}

(c) The Author(s). 2018 Open Access This article is distributed under the terms of the Creative Commons Attribution 4.0 International License (http://creativecommons.org/licenses/by/4.0/), which permits unrestricted use, distribution, and reproduction in any medium, provided you give appropriate credit to the original author(s) and the source, provide a link to the Creative Commons license, and indicate if changes were made. The Creative Commons Public Domain Dedication waiver (http://creativecommons.org/publicdomain/zero/1.0/) applies to the data made available in this article, unless otherwise stated. 


\section{Background}

Propofol is a common anesthetic agent for the induction of general anesthesia. Rapid infusion of propofol often causes hypotension [1-5]. Intraoperative hypotension may lead to negative outcomes such as myocardial injury, stroke, acute kidney injury, and death [6-10]. Conversely, laryngoscopy and tracheal intubation often cause hypertension [11-15]. Hypertension associated with intubation may cause negative outcomes such as myocardial infarction, heart failure, pulmonary edema, and cerebral and subarachnoid hemorrhage [16-18]. Thus, preventing hemodynamic fluctuations, or stabilizing hemodynamics, would avoid some harmful complications. The recommended dose of propofol in induction of general anesthesia is $2-2.5 \mathrm{mg} / \mathrm{kg}$.

The American Society of Anesthesiologists physical status (ASA-PS) scale is a widely used grading system to measure the preoperative health of surgical patients. The ASA-PS scale is a subjective assessment of a patient's overall health that is based on 6 categories (1 [healthy and no complications] to 6 [brain death]). Elderly patients and/or patients with ASA-PS scores of 3 or higher (having moderate to severe comorbidities) require a reduction in dose of propofol due to adverse prognosis [19-21]. However, the relationship between characteristics of patients and anesthesia induction dose of propofol has not yet been fully evaluated.

Since reliable guidelines for determining the propofol dose in anesthesia induction do not exist, this determination has been entrusted to each anesthesiologist. Although anesthetic devices and drugs have undergone improvements, intraoperative hemodynamic fluctuations continue to occur [22]. Structural equation modeling (SEM) is a multivariate statistical tool for evaluating complex relations in several research fields. SEM is a useful method for evaluating simultaneous causal associations among factors, which allows factors to be both dependent and independent. By explicitly accounting for the underlying roles of the factors of enhanced hemodynamic fluctuations, SEM can provide more insight and a better understanding of how risk factors influence the outcome.

The aims of this study were to identify the predictors of hemodynamic fluctuations after induction of general anesthesia and to develop a prediction formula, using SEM analysis, to calculate the appropriate propofol dose in induction.

\section{Materials and methods}

\section{Patient population and ethics}

Our retrospective cohort study protocol was approved by the Institutional Review Board (IRB) of Kyushu University Hospital in March 2018 (IRB\# 29-630). The IRB waived the need for written informed consent from participants. Because all patients received usual care and were not subjected to research activities, written informed consent was not obtained. This article adheres to the applicable Strengthening the Reporting of Observational Studies in Epidemiology (STROBE) guidelines.

Patients who were 18 years old or older (range: 18 to 96 years old) and underwent general anesthesia induction using propofol subsequently with tracheal intubation for non-cardiac surgery were included in this study. All patients $(n=2760)$ underwent inpatient anesthesia and surgery at the Kyushu University Hospital in Fukuoka, Japan, during the period April 2015 to March 2016. Patients who were missing important covariates regarding intubation or hemodynamic data were excluded $(n=56)$. Patients who did not receive oral intubation or who underwent repeated attempts at intubation were also excluded $(n=607)$. A total of 2097 participants were included in this analysis.

\section{Validation study of the prediction formula}

In another part of the study, the prediction formula was then applied to 1974 patients, who were admitted to the same hospital during the period April 2016 to March 2017 in order to validate the derived prediction formula. A sample size of 1974 patients was expected to yield sufficient subjects to validate the prediction formula. This separate cohort was comparable in confounders to the study cohort.

\section{Clinical data}

Preoperative patient clinical information was collected from anesthesia preoperative evaluation records (NIHON KOHDEN Corp, Tokyo, Japan). The records consisted of demographic data, laboratory data, and medical history. Intraoperative data were obtained from computerized anesthesia records (NIHON KOHDEN Corp.). These data from the patient monitoring system and anesthesia machine were automatically stored in anesthesia records, whereas drug dose and anesthesia techniques were registered manually. No patients received anesthetic premedication. In the operation room, the patients were placed on the operating table in the supine position. Baseline data, such as electrocardiography, non-invasive blood pressure, and pulse oximetry, were obtained from the records of standard monitors. An invasive arterial catheter was inserted after induction of general anesthesia if necessary. Heart rate was continuously recorded, and non-invasive arterial blood pressure was recorded every $2.5 \mathrm{~min}$. Basically, arterial blood pressure was recorded continuously after insertion of the invasive arterial catheter. Induction of general anesthesia was elicited by propofol, fentanyl, remifentanil, rocuronium, and inhalation anesthetics (sevoflurane or desflurane in oxygen). Propofol was administered 
according to the instruction manual. Selection of induction drugs and doses depended on the anesthesiologist's clinical judgment based on the patients' medical conditions. Laryngoscopy and orotracheal intubation were performed by an attending anesthesiologist (residents or specialists).

\section{Definition of main outcome}

Baseline arterial blood pressure (pre-induction) was defined as the first measurement in the operating room under awake conditions. While, arterial blood pressure after induction (post-induction) was measured within 3 min after tracheal intubation. In case of insertion of an invasive arterial catheter, arterial blood pressure $1 \mathrm{~min}$ after tracheal intubation was measured. Several definitions of hemodynamic fluctuations have been previously published. However, Bijker et al. reviewed the major journals and concluded that hypotension is best defined as $20-30 \%$ reduction of mean arterial blood pressure (MAP) [22]. In addition, Goldman et al. reported that postoperative cardiac death was significantly associated with a 33\% or greater fall in intraoperative systolic blood pressure (SBP) from baseline for more than $10 \mathrm{~min}$ [23]. Moreover, Bijker et al. reported that a decrease in MAP of more than $30 \%$ from baseline was associated with the occurrence of a postoperative stroke (odds ratio $[\mathrm{OR}]=1.013$ for every minute of hypotension, 99\% confidence interval $[\mathrm{CI}]=1.000-1.025)$ [7]. Based on the results mentioned above, if a patient's post-induction MAP decreased or increased $30 \%$ or more from their pre-induction MAP, they were determined to have enhanced hemodynamic fluctuations before and after anesthesia induction.

\section{Statistical analysis}

Differences in patient characteristics between the fluctuation status categories were compared using the Student t-test for normally distributed continuous variables and the Mann-Whitney U test for not-normally distributed continuous variables. Categorical variables were compared using the Pearson chi-squared test or the Fisher exact test where appropriate. Variables with a $P$ value of less than 0.20 in univariate analyses or clinical relevance were entered into the multivariate logistic regression model. Multivariate logistic regression analysis was used to adjust for potential confounding variables and to identify the association of independent variables with hemodynamic fluctuations. Similarly, variables with a $P$ value of less than 0.20 in multivariate analysis or clinical relevance were entered into SEM. SEM could be performed to simultaneously examine the direct and indirect effect of potential variables. A path coefficient indicates the direct effect of a variable assumed to be a cause on another variable assumed to be an effect [24]. As path coefficients are estimated from correlations, they should be standardized. In our study, SEM was used to reveal the propofol-mediated effect of potential variables to hemodynamic fluctuations and the effect of potential variables to propofol dose in anesthesia induction. The potential variables are often highly intercorrelated (multicollinearity). Multicollinearity was assessed using variance inflation factor (VIF) [25], which measures the inflation in the variances of the parameter estimates due to multicollinearity potentially caused by correlated predictors. Although there is no consensus as what cutoff based on values of VIF should be used to detect multicollinearity, VIF greater than 5 [25] is suggested for detecting multicollinearity.

To assess the accuracy of the prediction formula, we applied it to a separate cohort of 1974 patients. We defined differences less than $5 \mathrm{mg}$ between the actual dose and estimated dose as "fitted to the formula (fitted group)" and otherwise defined as "unfitted to the formula (unfitted group)".

Age, height, weight, blood pressure, and drug use except vasopressor at induction and intubation were treated as continuous variables. Remaining covariates, namely ASA-PS scale (scores of 1 or 2 and 3 or 4 ), obesity (body mass index $<25 \mathrm{~kg} / \mathrm{m}^{2}$ and $\geq 25 \mathrm{~kg} / \mathrm{m}^{2}$ ), anesthesia start time (forenoon and afternoon), a clinical history of comorbidities (positive and negative), vasopressor (use [phenylephrine $0.05-0.1 \mathrm{mg}$ or ephedrine 4-8 $\mathrm{mg}]$ or non-use) were treated as categorical variables. The 48 potential predictors as reported in the pre-existing literature, which may be associated with hemodynamic fluctuations in induction of general anesthesia, are shown in Table 1 . All $P$ values were 2 -sided, and those less than 0.05 were considered statistically significant. All statistical analyses were performed using Stata version 14.1 software (StataCorp LP, College Station, Texas, USA).

\section{Results}

Of 2760 consecutive non-cardiac surgical patients 18 years or older who underwent general anesthesia induction using propofol, 192 did not have orotracheal intubation, 415 underwent repeated attempts at tracheal intubation and 56 were missing important covariate data. Exclusion of these patients resulted in a sample size of 2097 patients (Fig. 1). Enhanced hemodynamic fluctuations after induction of general anesthesia were observed in 482 patients (23.0\%). Of these 482 patients, 287 (13.7\%) developed hypotension, and 195 (9.3\%) developed hypertension.

Tables 1 and 2 show differences in demographics and lifestyle-related and clinical features of the two fluctuation status groups. Age, history of ischemic heart disease, propofol dose, and fentanyl dose were significantly 
Table 1 Demographic, lifestyle-related, physical and clinical characteristics of perioperative patients according to hemodynamic fluctuation status $(n=2097)$

\begin{tabular}{|c|c|c|c|c|c|}
\hline \multirow[t]{2}{*}{ Variables } & \multicolumn{4}{|c|}{ Hemodynamic fluctuation } & \multirow[t]{2}{*}{$P$ value } \\
\hline & $\begin{array}{l}\geq 30 \% \\
(n=482)\end{array}$ & No. $^{a}$ & $\begin{array}{l}<30 \% \\
(n=1615)\end{array}$ & $\mathrm{No}^{a}$ & \\
\hline \multicolumn{6}{|l|}{ Demographic and lifestyle-related } \\
\hline Age (years), mean (range) & $61.2(18-96)$ & 0 & $58.3(18-93)$ & 0 & $<0.001$ \\
\hline Female sex, $n(\%)$ & $247(51.2)$ & 0 & $813(50.3)$ & 0 & 0.73 \\
\hline Height $(\mathrm{cm})$, mean $(95 \% \mathrm{Cl})$ & $160.5(159.7-161.4)$ & 0 & $161.0(160.6-161.5)$ & 3 & 0.29 \\
\hline Weight (kg), mean $(95 \% \mathrm{Cl})$ & $59.3(58.1-60.5)$ & 0 & $60.1(59.5-60.8)$ & 0 & 0.23 \\
\hline $\mathrm{BMI}, n(\%)$ & & 0 & & 3 & 0.23 \\
\hline$<18$ & $48(29.6)$ & & $114(70.4)$ & & \\
\hline$\geq 18,<25$ & $316(22.4)$ & & $1093(77.6)$ & & \\
\hline$\geq 25,<35$ & $110(22.5)$ & & $379(77.5)$ & & \\
\hline$\geq 35$ & $8(23.5)$ & & $26(76.5)$ & & \\
\hline Smoking history, $n(\%)$ & $226(46.9)$ & 0 & $721(44.8)$ & 5 & 0.42 \\
\hline \multicolumn{6}{|l|}{ Physical status } \\
\hline ASA-PS scale, $n(\%)$ & & 0 & & 0 & 0.52 \\
\hline 1 or 2 & $417(86.5)$ & & 1415 (87.6) & & \\
\hline 3 or 4 & $65(13.5)$ & & $200(12.4)$ & & \\
\hline Low exercise tolerability, $n$ (\%) & $32(6.7)$ & 1 & $91(5.7)$ & 5 & 0.41 \\
\hline \multicolumn{6}{|l|}{ Clinical and laboratory data } \\
\hline \multicolumn{6}{|c|}{ Arterial BP $(\mathrm{mmHg})$ in the ward, mean $(95 \% \mathrm{Cl})$} \\
\hline Systolic BP & $125(123-126)$ & 15 & $125(124-126)$ & 49 & 0.92 \\
\hline Diastolic BP & $74(73-75)$ & 16 & $74(74-75)$ & 51 & 0.82 \\
\hline History of steroid use, $n$ (\%) & $28(5.8)$ & 1 & $96(6.0)$ & 5 & 0.91 \\
\hline History of opioid use, $n(\%)$ & $3(0.6)$ & 1 & $13(0.8)$ & 5 & $1.00^{\mathrm{b}}$ \\
\hline Antithrombotic drug use, $n(\%)$ & $66(13.7)$ & 1 & $184(11.4)$ & 5 & 0.17 \\
\hline Anemia, $n(\%)$ & $172(35.8)$ & 1 & $573(35.5)$ & 2 & 0.93 \\
\hline Electrolyte imbalance, $n(\%)$ & $4(0.8)$ & 3 & $12(0.8)$ & 6 & $0.77^{\mathrm{b}}$ \\
\hline Hypoalbuminemia, $n$ (\%) & $70(14.6)$ & 3 & $191(11.9)$ & 6 & 0.11 \\
\hline Elevated CRP, n (\%) & $133(27.9)$ & 5 & $413(25.8)$ & 14 & 0.36 \\
\hline
\end{tabular}

Data are presented as $n(\%)$ for categorical variables, mean $(95 \% \mathrm{Cl})$ or mean (range) for continuous variables

$B M I$ Body mass index, ASA-PS American Society of Anesthesiologists physical status, BP Blood pressure, $C I$ Confidence interval, CRP C-reactive protein ${ }^{a}$ Number of missing patients

${ }^{b}$ Fisher's exact test

different between the two fluctuation status groups, whereas diabetes mellitus, peripheral vascular disease, and stroke appeared to be marginally significant. However, difference in two clinically important variables, namely ASA-PS score and sex, did not reach statistical significance.

Variables with a $P$ value of less than 0.20 in univariate analyses or two clinically important variables were entered into the multivariate logistic regression model. The results of multivariate logistic regression analysis are shown in Table 3 . Three potentially relevant $(P<0.20)$ variables with hemodynamic fluctuations, namely, ischemic heart disease (adjusted OR $=1.51,95 \% \mathrm{CI}=0.93-$
2.46, $P=0.10$ ), propofol dose (adjusted $\mathrm{OR}=0.81,95 \%$ $\mathrm{CI}=0.65-1.01, P=0.06$ ), and fentanyl dose (adjusted $\mathrm{OR}=0.84,95 \% \mathrm{CI}=0.69-1.02, P=0.08$ ), were extracted.

SEM predicting enhanced hemodynamic fluctuations in preoperative patients is shown in Fig. 2 and Table 4. The path coefficients $(r)$ indicated the direction and magnitude of the associations. Age $(r=-0.0113,95 \%$ $\mathrm{CI}=-0.0126-0.010, \quad P<0.001)$, ASA-PS score $(r=-$ $0.0788,95 \% \mathrm{CI}=-0.1431-0.0145, P=0.02)$, sex $(r=$ $0.057,95 \% \mathrm{CI}=0.0149-0.9906, P=0.01)$, and fentanyl dose $(r=0.1087, \quad 95 \% \quad \mathrm{CI}=0.0707-0.1467, \quad P<0.001)$ were significant factors that influenced the dose of propofol directly. The OR estimated using logistic 


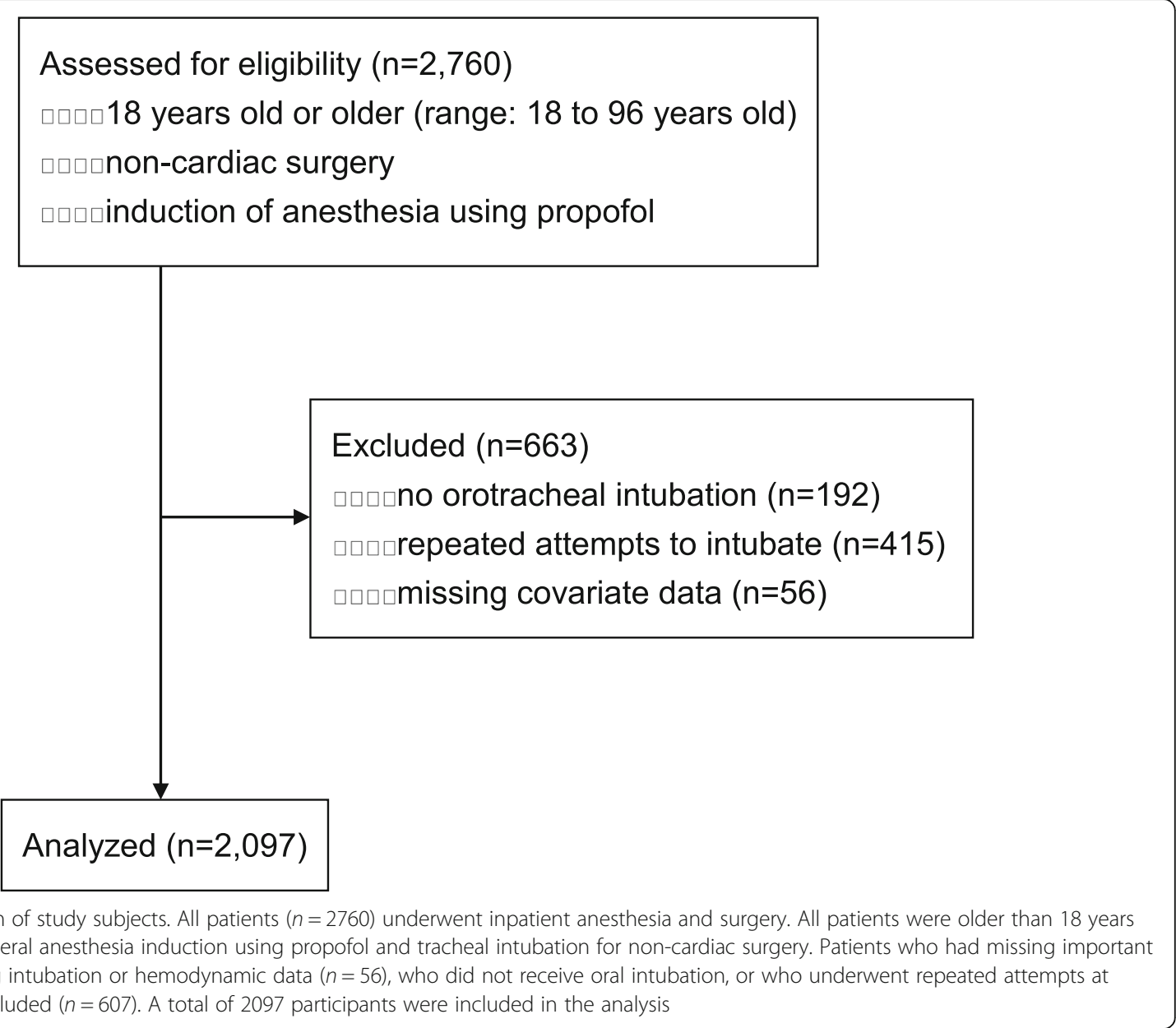

regression in SEM of enhanced hemodynamic fluctuations was significantly increased per age increment (1.008, 95\% CI $=1.001-1.015, P=0.03)$. Conversely, ischemic heart disease $(\mathrm{OR}=1.54,95 \% \mathrm{CI}=0.99-2.38$, $P=0.06)$, fentanyl dose $(\mathrm{OR}=0.83,95 \% \mathrm{CI}=0.69-1.01$, $P=0.06)$, and propofol dose ( $\mathrm{OR}=0.81,95 \% \mathrm{CI}=0.65$ $1.00, P=0.05)$ were non-significant. Based on the data in Table 4, the prediction formula of propofol dose in induction is as follows:

$$
\begin{aligned}
\text { Propofol dose }(m g)= & {[2.374-0.0113 \times \text { age }(\text { year })} \\
& -0.0788(\text { if ASA-PS } 3 \text { or } 4) \\
& +0.057(\text { if female })+0.1087 \\
& \times \text { fentanyl dose }(\mu \mathrm{g} / \mathrm{kg})] \\
& \times \text { body weight }(\mathrm{kg})
\end{aligned}
$$

As a result of the application of this formula to a validation cohort, the prevalence of hemodynamic fluctuations in the unfitted group $(26.7 \%, n=1654)$ was significantly higher than that in the fitted group
$(19.7 \%, n=320)(P=0.009)$. Since all VIF values were lower than 2 , we confirmed the absence of multicollinearity (data not shown).

\section{Discussion}

In our study, the prevalence of hemodynamic fluctuations after induction of general anesthesia was observed to be $23.0 \%$. Age $(\mathrm{OR}=1.008,95 \% \mathrm{CI}=1.001-1.015, P=0.03)$ was significantly associated with enhanced hemodynamic fluctuations. Whereas, ischemic heart disease $(\mathrm{OR}=1.54$, 95\% CI $=0.99-2.38, P=0.06)$, fentanyl dose $(\mathrm{OR}=0.83$, $95 \% \mathrm{CI}=0.69-1.01, P=0.06)$, and propofol dose $(\mathrm{OR}=$ $0.81,95 \% \mathrm{CI}=0.65-1.00, P=0.05)$ were marginally associated. Conversely, age $(r=-0.0113,95 \% \mathrm{CI}=-$ $0.0126-0.010, P<0.001)$, ASA-PS score $(r=-0.0788$, $95 \% \mathrm{CI}=-0.1431-0.0145, \quad P=0.02), \quad$ sex $\quad(r=0.057$, 95\% $\mathrm{CI}=0.0149-0.9906, P=0.01)$, and fentanyl dose $(r=0.1087,95 \% \mathrm{CI}=0.0707-0.1467, P<0.001)$ were significant factors that influenced the dose of propofol directly.

A recent study found that the prevalence of hypotension $(\mathrm{SBP}<80$ for $>5 \mathrm{~min}$ ) and hypertension 
Table 2 Clinical history and anesthetic practice of perioperative patients according to hemodynamic fluctuation status ( $\mathrm{n}=2097$ )

\begin{tabular}{|c|c|c|c|c|c|}
\hline \multirow[t]{2}{*}{ Variables } & \multicolumn{4}{|c|}{ Hemodynamic fluctuation } & \multirow[t]{2}{*}{$P$ value } \\
\hline & $\begin{array}{l}\geq 30 \% \\
(n=482)\end{array}$ & No. $^{a}$ & $\begin{array}{l}<30 \% \\
(n=1615)\end{array}$ & $\overline{\text { No. }^{a}}$ & \\
\hline \multicolumn{6}{|l|}{ Clinical history, $n(\%)$} \\
\hline Diabetes mellitus & $97(20.1)$ & 0 & $263(16.3)$ & 3 & 0.05 \\
\hline Hyperlipidemia & $108(22.4)$ & 0 & 309 (19.2) & 3 & 0.12 \\
\hline Hypertension & $208(43.2)$ & 0 & $673(41.2)$ & 3 & 0.58 \\
\hline Ischemic heart disease & $33(6.9)$ & 4 & $65(4.0)$ & 7 & 0.01 \\
\hline Congestive heart failure & $5(1.0)$ & 0 & $18(1.1)$ & 3 & 0.88 \\
\hline Arrhythmia & $19(3.9)$ & 0 & $70(4.3)$ & 3 & 0.70 \\
\hline Valvular heart disease & $17(3.5)$ & 0 & $76(4.7)$ & 3 & 0.27 \\
\hline Cardiomyopathy & $1(0.2)$ & 0 & $11(0.7)$ & 3 & $0.32^{\mathrm{b}}$ \\
\hline Pulmonary hypertension & $3(0.6)$ & 0 & $7(0.4)$ & 3 & $0.71^{\mathrm{b}}$ \\
\hline Peripheral vascular disease & $13(2.7)$ & 0 & $25(1.6)$ & 3 & 0.10 \\
\hline Aortic aneurysm & $6(1.2)$ & 0 & $9(0.6)$ & 3 & 0.12 \\
\hline Stroke & $35(7.3)$ & 0 & $84(5.2)$ & 3 & 0.09 \\
\hline Asthma & $32(6.6)$ & 0 & $118(7.3)$ & 3 & 0.61 \\
\hline Sleep apnea syndrome & $22(4.6)$ & 3 & $71(4.4)$ & 12 & 0.88 \\
\hline Chronic kidney disease & $120(25.1)$ & 3 & $368(22.9)$ & 6 & 0.32 \\
\hline Liver dysfunction & $9(1.9)$ & 5 & $28(1.8)$ & 16 & 0.84 \\
\hline Hyperthyroidism & $4(0.8)$ & 1 & $12(0.7)$ & 3 & 0.85 \\
\hline Hypothyroidism & $18(3.7)$ & 0 & $47(2.9)$ & 0 & 0.36 \\
\hline Rheumatoid arthritis & $7(1.5)$ & 1 & $16(1.0)$ & 5 & 0.39 \\
\hline Gastrointestinal disorder & $28(5.8)$ & 0 & $92(5.7)$ & 3 & 0.93 \\
\hline \multicolumn{6}{|l|}{ Operation and anesthesia, $n(\%)$} \\
\hline Emergency surgery & $31(6.4)$ & 0 & $96(5.9)$ & 0 & 0.69 \\
\hline Combined epidural anesthesia & $206(42.7)$ & 0 & $646(40.0)$ & 0 & 0.28 \\
\hline Anesthesia start time, $n(\%)$ & & 0 & & 0 & 0.17 \\
\hline A.M. & $294(61.0)$ & & $1041(64.5)$ & & \\
\hline P.M. & $188(39.0)$ & & $574(35.5)$ & & \\
\hline Intubation method, $n(\%)$ & & 3 & & 14 & 0.68 \\
\hline Direct & $406(84.8)$ & & $1369(85.5)$ & & \\
\hline Video laryngoscope & $73(15.2)$ & & $232(14.5)$ & & \\
\hline Operator of intubation, $n(\%)$ & & 0 & & 0 & 0.61 \\
\hline Specialist & $137(23.7)$ & & $440(76.3)$ & & \\
\hline Residents & $345(22.7)$ & & $1175(77.3)$ & & \\
\hline \multicolumn{6}{|c|}{ Drug dosage at induction and intubation, mean $(95 \% \mathrm{Cl})$ or median (range) } \\
\hline Propofol (mg/kg) & $1.8(1.7-1.8)$ & 0 & $1.9(1.9-1.9)$ & 0 & $<0.001$ \\
\hline Fentanyl $(\mu \mathrm{g} / \mathrm{kg})$ & $1.2(1.2-1.3)$ & 0 & $1.3(1.3-1.3)$ & 0 & 0.02 \\
\hline Remifentanil $\left(\mu \mathrm{kg}^{-1} \mathrm{~min}^{-1}\right)$ & $0.2(0-0.5)$ & 0 & $0.2(0-0.5)$ & 0 & 0.29 \\
\hline Sevoflurane (\%) & $0(0-3.3)$ & 0 & $0(0-6.2)$ & 0 & $0.70^{c}$ \\
\hline Desflurane (\%) & $0(0-5.0)$ & 0 & $0(0-8.0)$ & 1 & $0.74^{c}$ \\
\hline Midazolam (\%) & $0(0-5.0)$ & 0 & $0(0-4.0)$ & 1 & $0.17^{c}$ \\
\hline Vasopressor, $n$ (\%) & $19(3.9)$ & 0 & $51(3.2)$ & 0 & 0.40 \\
\hline
\end{tabular}

Data are presented as $n(\%)$ for categorical variables, mean $(95 \% \mathrm{Cl})$ or median (range) for continuous variables

A.M. Ante meridian, P.M. Post meridian, $\mathrm{Cl}$ Confidence interval

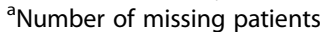

${ }^{\mathrm{b}}$ Fisher's exact test

'Mann-Whitney U test 
Table 3 Association between enhanced hemodynamic fluctuation ( $\geq 30 \%)$ and selected clinical factors

\begin{tabular}{|c|c|c|c|c|}
\hline \multirow[t]{2}{*}{ Variables } & \multicolumn{4}{|l|}{ OR $(95 \% \mathrm{Cl})$} \\
\hline & Crude & $P$ value & Adjusted $^{a}$ & $P$ value \\
\hline Age (year) & $1.01(1.01-1.02)$ & $<0.001$ & - & \\
\hline Female sex & $1.04(0.85-1.27)$ & 0.73 & - & \\
\hline ASA-PS scale, 3 or 4 vs. 1 or 2 & $1.10(0.82-1.49)$ & 0.53 & $0.87(0.62-1.24)$ & 0.45 \\
\hline Anesthesia start time, P.M. vs. A.M. & $1.16(0.94-1.43)$ & 0.17 & $1.14(0.92-1.41)$ & 0.22 \\
\hline Ischemic heart disease & $1.76(1.14-2.71)$ & 0.01 & $1.51(0.93-2.46)$ & 0.10 \\
\hline Peripheral vascular disease & $1.76(0.89-3.47)$ & 0.11 & $1.39(0.67-2.88)$ & 0.38 \\
\hline Aortic aneurysm & $2.25(0.80-6.34)$ & 0.14 & $1.55(0.51-4.70)$ & 0.44 \\
\hline Stroke & $1.42(0.95-2.14)$ & 0.10 & $1.23(0.77-1.95)$ & 0.38 \\
\hline Diabetes mellitus & $1.29(0.99-1.67)$ & 0.06 & $1.12(0.85-1.48)$ & 0.41 \\
\hline Hyperlipidemia & $1.22(0.95-1.56)$ & 0.12 & $1.03(0.79-1.35)$ & 0.82 \\
\hline Hypoalbminemia & $1.27(0.95-1.71)$ & 0.12 & $1.17(0.85-1.61)$ & 0.34 \\
\hline Antithrombotic drug use & $1.23(0.91-1.67)$ & 0.18 & $0.91(0.63-1.32)$ & 0.62 \\
\hline Propofol (mg/kg) & $0.71(0.59-0.87)$ & $<0.001$ & $0.81(0.65-1.01)$ & 0.06 \\
\hline Fentanyl ( $\mu \mathrm{g} / \mathrm{kg})$ & $0.80(0.66-0.96)$ & 0.02 & $0.84(0.69-1.02)$ & 0.08 \\
\hline Midazolam (mg) & $0.75(0.47-1.20)$ & 0.18 & $0.79(0.49-1.27)$ & 0.33 \\
\hline
\end{tabular}

${ }^{a}$ Mutually adjusted for all variables in Table 3

ASA-PS American Society of Anesthesiologists physical status, OR Odds ratio, CI Confidence interval

(SBP > 160 for $>5 \mathrm{~min}$ ) were 26 and $20 \%$, respectively [26]. Similarly, $25 \%$ of patients had arterial blood pressure fluctuations greater than 30\% during anesthesia induction using propofol [27]. Therefore, the prevalence in our study of hemodynamic fluctuations after induction of general anesthesia was similar to the prevalence reported in other studies.
The recommended dose of propofol in induction is $2-2.5 \mathrm{mg} / \mathrm{kg}$. Since geriatric patients and patients with ASA-PS scores of 3 or higher are more sensitive to the anesthetic and adverse effects, a dose reduction is recommended. In fact, predictors of hypotension after induction were ASA-PS score of 3 or 4 and age older than 50 years [1]. Also, age 65 years or older

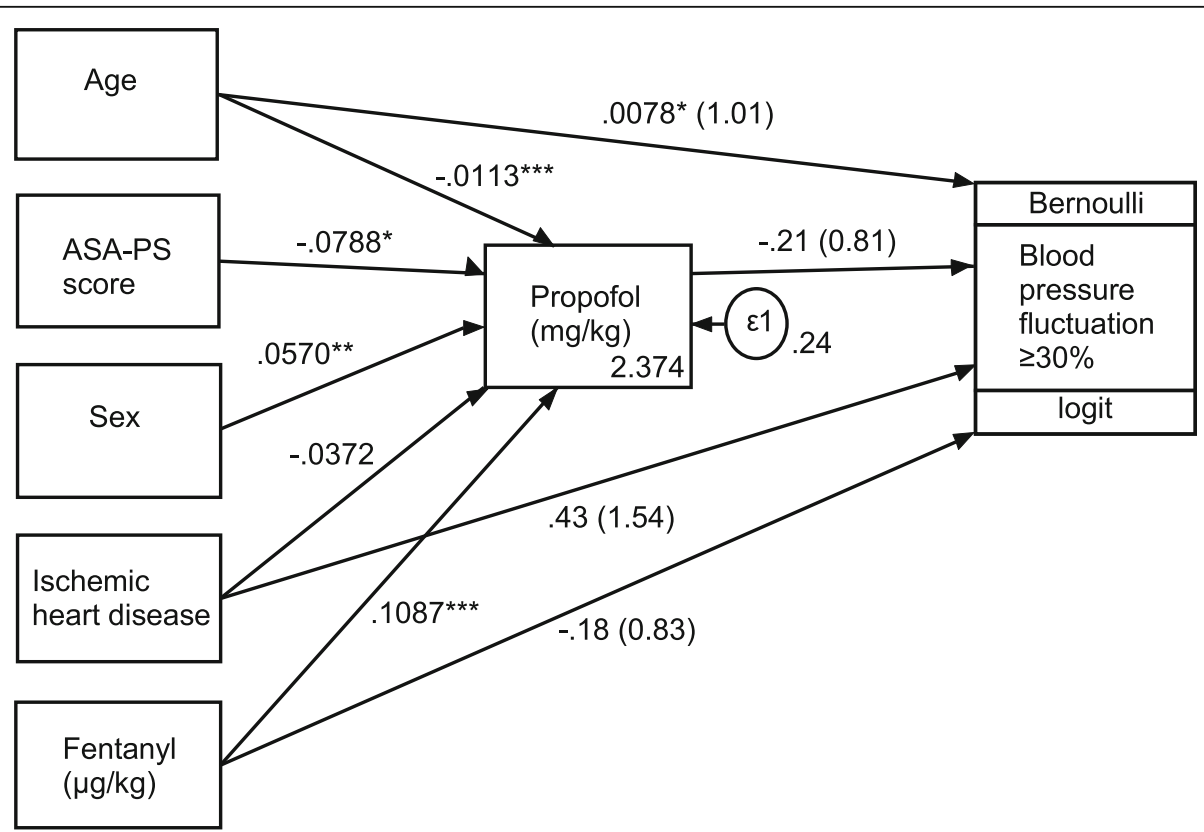

Fig. 2 Factors predicting enhanced blood pressure fluctuation with path coefficients and odds ratios (in parentheses) $(n=2097)$. ASA-PS American Society of Anesthesiologists physical status. Numbers by the arrow lines represent the estimated coefficients with significance level: ${ }^{*} P<0.05$; ${ }^{* *} P<0.01 ;{ }^{* *} P<0.001$. $\varepsilon 1$ : dependent variable 
Table 4 Structural equation model of enhanced hemodynamic fluctuation ( $\geq 30 \%)$

\begin{tabular}{lll}
\hline Variables & Model coefficient $(95 \% \mathrm{Cl})$ & $P$ value \\
Propofol dose & Regression coefficient $(r)$ & $<0.001$ \\
\hline Age (year, continuous) & $-0.0113(-0.0126-0.0100)$ & 0.02 \\
ASA-PS scale & $-0.0788(-0.1431-0.0145)$ & 0.01 \\
Sex & $0.0570(0.0149-0.9906)$ & 0.47 \\
Ischemic heart disease & $-0.0372(-0.1388-0.0645)$ & $<0.001$ \\
Fentanyl $(\mu \mathrm{g} / \mathrm{kg})$ & $0.1087(0.0707-0.1467)$ & $P$ value \\
Constant & $2.374(2.275-2.473)$ & 0.03 \\
Enhanced hemodynamic fluctuation $(\geq 30 \%)$ & OR (95\% Cl) & 0.06 \\
Age (year, continuous) & $1.008(1.001-1.015)$ & 0.06 \\
Ischemic heart disease & $1.536(0.990-2.382)$ & 0.05 \\
Fentanyl $(\mu \mathrm{g} / \mathrm{kg})$ & $0.831(0.687-1.005)$ & $0.807(0.652-1.000)$ \\
Propofol $(\mathrm{mg} / \mathrm{kg})$ & &
\end{tabular}

ASA-PS American Society of Anesthesiologists physical status, Cl Confidence interval, OR Odds ratio

and higher dose of propofol were major two highly significant predictive factors for hypotension caused by propofol injection [2]. Additionally, the favorable induction dose of propofol in patients younger than 60 years was $2.25-2.5 \mathrm{mg} / \mathrm{kg}$, whereas in patients older than 60 years was $1.5-1.75 \mathrm{mg} / \mathrm{kg}$ [21]. The induction dose of propofol should be adjusted for an individual patient's condition.

To determine the suitable dose of propofol to protect against hemodynamic fluctuations, we investigated the relation of propofol dose in induction to hemodynamic fluctuations. As shown in Table 4, age, sex, ASA-PS score, and fentanyl dose were associated with propofol dose to stabilize hemodynamic responses in induction.

Previous studies have provided consistent evidence for relationships between age and ASA-PS and enhanced hemodynamic fluctuation $[1,2,21]$. On the other hand, there was no difference that the effect of sex on the propofol dose in relation to loss of consciousness [28]. Similarly, a logistic regression model was used to predict blood pressure change caused by rapid injection of propofol during anesthesia induction [27]. It found that sex did not significantly contribute to blood pressure change. However, females were more likely to become hypotensive than males [2] and the half maximal effective concentration of propofol in males was significantly higher than females [29]. In our study, sex was not related to hemodynamic changes, but females required higher doses of propofol in induction than males.

Increasing the induction dose of fentanyl was a predictive factor for hypotension [1]. Similarly, concomitant use of opioids was a minor risk factor for hypotension caused by propofol [2]. Conversely, five $\mu \mathrm{g} / \mathrm{kg}$ of fentanyl treatment caused a significant attenuation of the blood pressure response to laryngoscopy and intubation [30]. The magnitude of post-intubation hypertension was reported to be significantly less according to an increase in the fentanyl dose $(P<0.05$ for 2 or $4 \mu \mathrm{g} / \mathrm{kg}$ vs. no fentanyl; $P<0.05$ for $4 \mu \mathrm{g} / \mathrm{kg}$ vs. $2 \mu \mathrm{g} / \mathrm{kg}$ ) [31].

Fentanyl was shown to cause and promote hypotension [1,2]. On the other hand, the addition of fentanyl prior to propofol induction is used to decrease propofol dose and hypertensive response to tracheal intubation [30-32]. In our study, $1.3 \mu \mathrm{g} / \mathrm{kg}$ of fentanyl for the stable group (MAP change $<30 \%$ ) and $1.2 \mu \mathrm{g} / \mathrm{kg}$ for the unstable group (MAP change $\geq 30 \%$ ) were administered for anesthetic induction $(P<0.001)$. This result suggests that the preventive effect of fentanyl on hypertension is more dominant than the promoting effect of fentanyl on hypotension. Consequently, the propofol dose in induction increased with the increasing fentanyl dose (Table 4 and Fig. 2). Therefore, our formula indicating a positive association between propofol dose and fentanyl dose may be biologically plausible.

Our retrospective cohort study has several limitations. Generally, the researchers retrospectively identify the exposure and the outcome information. Selection bias would be possible if participation had been influenced by the physical status of patients. However, patients who had severe comorbidities could not be induced with general anesthesia using propofol. Moreover, data were entered manually during anesthesia (such as administration of medications and time of intubation). Since post-intubation blood pressure frequently reached its highest value at $0-1 \mathrm{~min}$ after intubation [30,33], it may be a less reliable estimate of the exact time of induction and intubation. Because the timing of blood pressure measurement after intubation was unfixed, it may be also less reliable. Another limitation of our study is that outcome information could not be obtained using our current data system. Cooperation with other relevant diagnosis and treatment department is crucial in the future studies. 
Advantages of our single-institution study are the large size of the study population, systematic consideration of potential confounders, and uniform collection of information about anesthetic practices. To estimate the generalizable prediction formula, almost all variables that affect hemodynamic fluctuations were considered; we also included a broad spectrum of patients in terms of surgical types and comorbidities. Several similar studies examining the relation of potential predictors to hemodynamic change have been reported [19, 27, 34-36]. However, since the variables to be entered in the prediction formula were either too few or too many, this was not clinically practical. Five variables, namely age, sex, ASA-PS score, fentanyl dose, and body weight, extracted from this study can be easily obtained from any patient and are essential factors for anesthesia. Therefore, our prediction formula is readily available at the time of anesthesia. A simple, generalized formula for choosing propofol dose should be required, especially for inexperienced anesthesiologists.

\section{Conclusions}

Age, ischemic heart disease, fentanyl dose and propofol dose were marginally or significantly associated with enhanced hemodynamic fluctuations in induction. The prediction formula derived to prevent hemodynamic fluctuations will help anesthesiologists tailor the dose of propofol in the induction of general anesthesia to each patient. Although the derived prediction formula is considered to be acceptable, future studies validating whether it can predict a patient's risk of enhanced hemodynamic fluctuations in clinical situations are necessary.

\section{Abbreviations}

ASA: American Society of Anesthesiologists; BMI: Body mass index; BP: Blood pressure; Cl: Confidence interval; CRP: C-reactive protein; IRB: Institutional Review Board; MAP: Mean arterial blood pressure; OR: Odds ratio; PS: Physical status; SBP: Systolic blood pressure; SEM: Structural equation modeling; STROBE: Strengthening the Reporting of Observational Studies in Epidemiology; VIF: Variance inflation factor

\section{Acknowledgements}

Not applicable.

\section{Funding}

Not applicable.

\section{Availability of data and materials}

The datasets generated and analyzed during the current study are not publicly available due to the institutional restrictions but are available from the corresponding author on reasonable request.

\section{Authors' contributions}

SK designs the study, acquire and analyze the data, and write the article. CK design and supervise the study, analyze the data, and write the article. ST supervise the study and data analysis. SH supervise the study and revise the article. All authors read and approved the final manuscript.

\section{Ethics approval and consent to participate}

This retrospective cohort study protocol was approved by the Institutional Review Board of Kyushu University Hospital in March 2018 (IRB\# 29-630). The IRB waived the need for written informed consent from participants because all patients received usual care and were not subjected to research activities.

\section{Consent for publication}

Not applicable.

\section{Competing interests}

The authors declare that they have no competing interests.

\section{Publisher's Note}

Springer Nature remains neutral with regard to jurisdictional claims in published maps and institutional affiliations.

\section{Author details}

${ }^{1}$ Department of Anesthesiology and Critical Care Medicine, Graduate School of Medical Sciences, Kyushu University, Maidashi 3-1-1, Higashi-ku, Fukuoka, Fukuoka, Japan. ${ }^{2}$ Department of Preventive Medicine, Graduate School of Medical Sciences, Kyushu University, Maidashi 3-1-1, Higashi-ku, Fukuoka, Fukuoka, Japan. ${ }^{3}$ Medical Information Center, Kyushu University Hospital, Maidashi 3-1-1, Higashi-ku, Fukuoka, Fukuoka, Japan.

Received: 31 May 2018 Accepted: 30 October 2018 Published online: 10 November 2018

\section{References}

1. Reich DL, Hossain S, Krol M, Baez B, Patel P, Bernstein A, et al. Predictors of hypotension after induction of general anesthesia. Anesth Analg. 2005:101:622-8 table of contents.

2. Hug CC Jr, McLeskey CH, Nahrwold ML, Roizen MF, Stanley TH, Thisted RA, et al. Hemodynamic effects of propofol: data from over 25,000 patients. Anesth Analg. 1993;77:S21-9.

3. Coates DP, Monk CR, Prys-Roberts C, Turtle M. Hemodynamic effects of infusions of the emulsion formulation of propofol during nitrous oxide anesthesia in humans. Anesth Analg. 1987;66:64-70.

4. Grounds RM, Twigley AJ, Carli F, Whitwam JG, Morgan M. The haemodynamic effects of intravenous induction. Comparison of the effects of thiopentone and propofol. Anaesthesia. 1985;40:735-40.

5. Aggarwal S, Goyal VK, Chaturvedi SK, Mathur V, Baj B, Kumar A. A comparative study between propofol and etomidate in patients under general anesthesia. Braz J Anesthesiol. 2016;66:237-41.

6. Group PS, Devereaux PJ, Yang H, Yusuf S, Guyatt G, Leslie K, et al. Effects of extended-release metoprolol succinate in patients undergoing non-cardiac surgery (POISE trial): a randomised controlled trial. Lancet. 2008:371:1839-47.

7. Bijker JB, Persoon S, Peelen LM, Moons KG, Kalkman CJ, Kappelle LJ, et al. Intraoperative hypotension and perioperative ischemic stroke after general surgery: a nested case-control study. Anesthesiology. 2012;116:658-64.

8. Walsh M, Devereaux PJ, Garg AX, Kurz A, Turan A, Rodseth RN, et al. Relationship between intraoperative mean arterial pressure and clinical outcomes after noncardiac surgery: toward an empirical definition of hypotension. Anesthesiology. 2013;119:507-15.

9. Bijker JB, van Klei WA, Vergouwe Y, Eleveld DJ, van Wolfswinkel L, Moons $K G$, et al. Intraoperative hypotension and 1-year mortality after noncardiac surgery. Anesthesiology. 2009;111:1217-26.

10. Monk TG, Bronsert MR, Henderson WG, Mangione MP, Sum-Ping ST, Bentt $\mathrm{DR}$, et al. Association between intraoperative hypotension and hypertension and 30-day postoperative mortality in noncardiac surgery. Anesthesiology. 2015;123:307-19.

11. Forbes AM, Dally FG. Acute hypertension during induction of anaesthesia and endotracheal intubation in normotensive man. $\mathrm{Br} J$ Anaesth. 1970;42:618-24

12. Prys-Roberts C, Greene LT, Meloche R, Foex P. Studies of anaesthesia in relation to hypertension. II. Haemodynamic consequences of induction and endotracheal intubation. Br J Anaesth. 1971:43:531-47.

13. Russell WJ, Morris RG, Frewin DB, Drew SE. Changes in plasma catecholamine concentrations during endotracheal intubation. $\mathrm{Br} J$ Anaesth 1981;53:837-9. 
14. Thomson IR. The haemodynamic response to intubation: a perspective. Can J Anaesth. 1989;36:367-9.

15. Rajbhandari PK. Lignocaine and Esmolol on stress response to laryngoscopy and intubation. JNMA J Nepal Med Assoc. 2014;52:775-9.

16. Edwards ND, Alford AM, Dobson PM, Peacock JE, Reilly CS. Myocardial ischaemia during tracheal intubation and extubation. $\mathrm{Br} J$ Anaesth. 1994;73:537-9.

17. Fox EJ, Sklar GS, Hill CH, Villanueva R, King BD. Complications related to the pressor response to endotracheal intubation. Anesthesiology. 1977;47:524-5.

18. Haku E, Hayashi M, Kato H. Anesthetic management of abdominal aortic surgery: a retrospective review of perioperative complications. J Cardiothorac Anesth. 1989;3:587-91.

19. Phillips AT, Deiner S, Mo Lin H, Andreopoulos E, Silverstein J, Levin MA. Propofol use in the elderly population: prevalence of overdose and association with 30-day mortality. Clin Ther. 2015;37:2676-85.

20. Steib A, Freys G, Beller JP, Curzola U, Otteni JC. Propofol in elderly high risk patients. A comparison of haemodynamic effects with thiopentone during induction of anaesthesia. Anaesthesia. 1988;43:Suppl:111-4.

21. Dundee JW, Robinson FP, McCollum JS, Patterson CC. Sensitivity to propofol in the elderly. Anaesthesia. 1986;41:482-5.

22. Bijker JB, van Klei WA, Kappen TH, van Wolfswinkel L, Moons KG, Kalkman $\mathrm{CJ}$. Incidence of intraoperative hypotension as a function of the chosen definition: literature definitions applied to a retrospective cohort using automated data collection. Anesthesiology. 2007:107:213-20.

23. Goldman L, Caldera DL, Southwick FS, Nussbaum SR, Murray B, O'Malley TA, et al. Cardiac risk factors and complications in non-cardiac surgery. Medicine (Baltimore). 1978:57:357-70.

24. Kerlinger FN, Pedhazur EJ. Multiple regression in behavioral research. New York: Holt, Rinehart \& Winston; 1973.

25. Kutner MH, Nachtsheim CJ, Neter J, Li W. Applied Linear Statistical Models 5th Edition. New York: McGraw-Hill//rwin; 2004

26. Nair BG, Horibe M, Newman SF, Wu WY, Peterson GN, Schwid HA. Anesthesia information management system-based near real-time decision support to manage intraoperative hypotension and hypertension. Anesth Analg. 2014;118:206-14

27. Rau RH, Li YC, Cheng JK, Chen CC, Ko YP, Huang CJ. Predicting blood pressure change caused by rapid injection of propofol during anesthesia induction with a logistic regression model. Acta Anaesthesiol Taiwanica. 2004:42:81-6.

28. Leslie K, Crankshaw DP. Lean tissue mass is a useful predictor of induction dose requirements for propofol. Anaesth Intensive Care. 1991;19:57-60.

29. Choi JJ, Kim JY, Lee D, Chang YJ, Cho NR, Kwak HJ. Male patients require higher optimal effect-site concentrations of propofol during i-gel insertion with dexmedetomidine $0.5 \mathrm{mug} / \mathrm{kg}$. BMC Anesthesiol. 2016;16:20.

30. Dahlgren N, Messeter K. Treatment of stress response to laryngoscopy and intubation with fentanyl. Anaesthesia. 1981;36:1022-6.

31. Billard V, Moulla F, Bourgain JL, Megnigbeto A, Stanski DR. Hemodynamic response to induction and intubation. Propofol/fentanyl interaction. Anesthesiology. 1994;81:1384-93.

32. Li S, Yu F, Zhu H, Yang Y, Yang L, Lian J. The median effective concentration (EC50) of propofol with different doses of fentanyl during colonoscopy in elderly patients. BMC Anesthesiol. 2016;16:24.

33. Helfman SM, Gold MI, DeLisser EA, Herrington CA. Which drug prevents tachycardia and hypertension associated with tracheal intubation: lidocaine, fentanyl, or esmolol? Anesth Analg. 1991;72:482-6.

34. Kazama T, Ikeda K, Morita K, Kikura M, Ikeda T, Kurita T, et al. Investigation of effective anesthesia induction doses using a wide range of infusion rates with undiluted and diluted propofol. Anesthesiology. 2000;92:1017-28.

35. Adachi YU, Watanabe K, Higuchi H, Satoh T. The determinants of propofol induction of anesthesia dose. Anesth Analg. 2001;92:656-61.

36. Gurses E, Sungurtekin H, Tomatir E, Dogan H. Assessing propofol induction of anesthesia dose using bispectral index analysis. Anesth Analg. 2004:98:128-31 table of contents.

\section{Ready to submit your research? Choose BMC and benefit from:}

- fast, convenient online submission

- thorough peer review by experienced researchers in your field

- rapid publication on acceptance

- support for research data, including large and complex data types

- gold Open Access which fosters wider collaboration and increased citations

- maximum visibility for your research: over $100 \mathrm{M}$ website views per year

At BMC, research is always in progress.

Learn more biomedcentral.com/submissions 